\title{
Anode Material Synthesized from Red Phosphorus and Germanium Nanowires for Lithium-Ion and Sodium-Ion Batteries
}

Tatiana Kulova ${ }^{1}$, Dmitri Gryzlov ${ }^{1}$, Alexander Skundin ${ }^{1}$, Ilia Gavrilin ${ }^{1,2}$, Yulia Kudryashova ${ }^{1}$, Nicolai Pokryshkin ${ }^{3}$

${ }^{1}$ Frumkin Institute of Physical Chemistry and Electrochemistry of the RAS, 31-4 Leninskii ave., 119071 Moscow, Russia

${ }^{2}$ National Research University of Electronic Technology (MIET), Bld. 1, Shokin Square, Zelenograd, 124498, Moscow Russia

${ }^{3}$ National Research Nuclear University (MEPHI), 31, Kashirskoe ave., 115409, Moscow Russia

*E-mail: askundin@mail.ru

Received: 26 August 2021 / Accepted: 28 September 2021 / Published: 10 November 2021

Germanium phosphide $(\mathrm{GeP})$ is synthesized by red phosphorus evaporation-condensation on the surface of germanium nanowires pre-grown on a titanium substrate. The synthesized GeP was found to be capable of reversibly inserting lithium and sodium. The effective diffusion coefficients of lithium and sodium in germanium phosphide are distinguished by 2 orders of magnitude and amounted to $10^{-12}$ and $10^{-14} \mathrm{~cm}^{2} / \mathrm{s}$, respectively.

Keywords: germanium, germanium phosphide, lithium and sodium diffusion coefficient, lithium-ion battery, sodium-ion battery.

\section{$\underline{\text { FULL TEXT }}$}

(C) 2021 The Authors. Published by ESG (www.electrochemsci.org). This article is an open access article distributed under the terms and conditions of the Creative Commons Attribution license (http://creativecommons.org/licenses/by/4.0/). 